\title{
Out-of-hospital cardiac arrest in patients without clinically significant coronary artery disease: comparison of clinical, electrophysiological, and survival characteristics with those in similar patients who have clinically significant coronary artery disease
}

\author{
CHRISTOPHER J MCLARAN, $†$ BERNARD J GERSH, „ DECLAN D SUGRUE, \\ STEPHEN C HAMMILL, * ALAN R ZINSMEISTER, DOUGLAS L WOOD, * \\ DAVID R HOLMES JR, ^ MICHAEL J OSBORN` \\ From the ${ }^{\star}$ Division of Cardiovascular Diseases and Internal Medicine, and the $\ddagger$ Section of Medical Research \\ Statistics, Mayo Clinic and Mayo Foundation, Rochester, Minnesota, USA
}

SUMMARY Fifty nine survivors of out-of-hospital cardiac arrest unassociated with an acute myocardial infarction were referred for intracardiac electrophysiological study. Thirty patients who had no clinically significant coronary artery disease (group 1) were compared with 29 who did (group 2). Ventricular tachycardia or fibrillation was induced in significantly more patients in group 2 than in group $1(69 \%$ vs $40 \%)$. Median duration of follow up, which was achieved in all patients, was 31 months in group 1 and 14 months in group 2. In group 1, an effective treatment was identified electrophysiologically in seven patients, and none died; an arrhythmia was induced, but no effective treatment was identified in five patients, and one patient died subsequently; an arrhythmia was not induced in 18 patients, 15 of whom were treated empirically with antiarrhythmic drugs, and one died. In group 2, effective treatment was identified electrophysiologically in seven patients and three died (two of pump failure) during follow up. In 13 an arrhythmia was induced but no effective drug was identified, and six died or had a recurrence; in another nine patients without inducible arrhythmias, six subsequently died or had a recurrence. A Cox proportional hazards analysis identified previous myocardial infarction as the only predictor of recurrence.

Patients without coronary artery disease who suffer an out-of-hospital cardiac arrest have a low inducibility rate at electrophysiological study and an excellent prognosis compared with patients who have coronary artery disease. Electrophysiological testing seemed to be of value in predicting the response to antiarrhythmic drugs, but non-inducibility of arrhythmias in patients with coronary artery disease was of no predictive value. Abstract presented at the Annual Meeting of the Scientific Session
of the American Heart Association, Washington, DC, 11 to 14
November 1985.

†Present address: The Prince Charles Hospital, Rode Road, Chermside, Brisbane, Australia 4032.

Requests for reprints to Dr Bernard J Gersh, Mayo Clinic, 200 First Street SW, Rochester, Minnesota, 55905, USA.

Accepted for publication 6 August 1987
Patients who experience an out-of-hospital cardiac arrest unassociated with acute myocardial infarction have a high recurrence rate. ${ }^{12}$ Recently, invasive electrophysiological testing has been suggested as a useful method of assessing the efficacy of antiarrhythmic treatment in these patients. ${ }^{3-5}$ If the arrhythmia cannot be induced while the patient is on antiarrhythmic drug treatment, long term survival is improved. ${ }^{4-6}$ In reported series most patients have had underlying coronary artery disease. ${ }^{578}$ There is 
little information on the role of electrophysiological study and its impact on survival in patients without coronary artery disease who have had an out-ofhospital cardiac arrest. The present study compares the clinical features, the results of electrophysiological study, and survival characteristics in two groups of patients-one with and one without coronary artery disease-who were resuscitated after an out-of-hospital cardiac arrest unassociated with acute myocardial infarction.

\section{Patients and methods}

\section{PATIENTS}

Fifty nine patients ( 36 male, 23 female; mean age 52 years, range 5-73) who had survived an out-ofhospital cardiac arrest not associated with an acute myocardial infarction were referred for electrophysiological study between November 1978 and February 1984. In all patients the rhythm at the time of the cardiac arrest was noted ( 46 had ventricular fibrillation and 13 had ventricular tachycardia), and an associated acute myocardial infarction was excluded by the absence of the typical evolution of electrocardiographic changes or the usual pattern of increase in cardiac enzyme activity. In 55 patients, an adequate estimate of left ventricular ejection fraction was obtained by contrast or radionuclide angiography or cross sectional echocardiography. Forty one patients underwent coronary arteriography.

All patients were followed up either by telephone interview or by direct examination.

PATIENTS WITHOUT CLINICALLY SIGNIFICANT CORONARY ARTERY DISEASE (GROUP 1)

Thirty patients did not have clinically significant coronary artery disease, as shown by angiographically normal vessels or haemodynamically insignificant disease at coronary arteriography (18 patients), a normal maximal treadmill stress test ( 3 patients), and absence of historical and electrocardiographic evidence of myocardial ischaemia (nine patients). In this last group of nine patients, four were female and three were male who were less than 35 years old (mean, 24 years). The two other patients were men aged 58 and 73; one had the Wolff-Parkinson-White syndrome and the other had clinical features of an idiopathic dilated cardiomyopathy. Table 1 gives the clinical details. In two of the seven patients without overt clinical heart disease, endomyocardial biopsy (right ventricle) showed mild non-specific focal changes of fibrosis without inflammation, the importance of which is uncertain. ${ }^{9}$ All seven had normal exercise tolerance,
12 lead electrocardiograms, and left ventricular ejection fractions.

PATIENTS WITH CORONARY ARTERY DISEASE (GROUP 2)

Twenty nine patients had clinical evidence of important coronary artery disease. Criteria for the diagnosis of coronary artery disease included the following: (a) important coronary artery disease $(>70 \%$ reduction in coronary arterial luminal diameter) at coronary arteriography (23 patients); (b) previous history of myocardial infarction (five patients); and (c) history of typical exertional angina pectoris (one patient).

\section{ELECTROPHYSIOLOGICAL STUDY}

Electrophysiological study was performed within eight weeks of the arrest in 49 patients and between four and 28 months in 10 patients. No patient studied four months or more after cardiac arrest had a recurrence between the time of the arrest and the initial study; some were treated empirically with antiarrhythmic agents. All patients gave informed consent and were studied in the postabsorptive, non-sedated state. All but three had stopped antiarrhythmic drug treatment for at least five half lives before study; the three patients who were on drugs had had recurrent spontaneous arrhythmias since their cardiac arrest that subsequently were apparently controlled by antiarrhythmic medication. Cardiac glycosides were continued in therapeutic doses if clinically indicated. Serum potassium concentration was normal in all patients at the time of study.

One to four standard 7F multielectrode catheter electrodes were inserted percutaneously via the femoral veins or right internal jugular vein and positioned in the right ventricular apex (all patients) and, as clinically indicated, in the high right atrium, His bundle area, and coronary sinus. The pacing protocol used during the electrophysiological study evolved over time. Ventricular stimulation was performed with a Medtronic 5325 stimulator capable of delivering one or two extrastimuli (the first 29 patients) or a Medtronic 2332 stimulator capable of delivering multiple extrastimuli (the last 30 patients) at twice diastolic threshold with a pulse width of $1.9 \mathrm{~ms}$.

Extrastimuli were introduced during sinus rhythm and during two paced rhythms (usually 100 and 150 beats/min), starting with a single stimulus that was used to scan diastole in 20 ms steps until the ventricular effective refractory period was reached. The first stimulus was then advanced by $30 \mathrm{~ms}$ and a second stimulus scanned diastole until refractoriness 
le 1 Clinical details, results of electrophysiological study, treatment, and follow up in patients without coronary artery disease

\begin{tabular}{|c|c|c|c|c|c|c|c|}
\hline $\begin{array}{ll}\text { Cardiac } \\
\text { ent diagnosis }\end{array}$ & $\begin{array}{l}\text { Age (yr) } \\
\text { and sex }\end{array}$ & $\begin{array}{l}\text { LVEF } \\
(\%)\end{array}$ & $\begin{array}{l}\text { Stimulation } \\
\text { protocol }\end{array}$ & $\begin{array}{l}\text { Arrhythmia } \\
\text { induced }\end{array}$ & $\begin{array}{l}\text { Treatment } \\
\text { predicted } \\
\text { to be } \\
\text { successful }\end{array}$ & $\begin{array}{l}\text { Follow up } \\
\text { (months) }\end{array}$ & Treatment \\
\hline $\mathbf{C M}$ & $23, F$ & 42 & P, Iso & Sust VT & - & 32 & \multirow{9}{*}{$\begin{array}{l}\text { Tocainide, } \\
\text { mexiletine } \\
\text { Amiodarone } \\
\text { Tocainide } \\
\text { Mexiletine } \\
\text { Procainamide } \\
\text { Amiodarone } \\
\text { Quinidine } \\
\text { Procainamide } \\
\text { Procainamide } \\
\text { Mexiletine } \\
\text { Quinidine } \\
\beta \text { blocker } \\
\text { Amiodarone } \\
\text { Mexiletine } \\
\text { Quinidine, } \\
\text { mexiletine } \\
\text { Amiodarone } \\
\beta \text { blocker } \\
\text { Disopyramide, } \\
\text { amiodarone } \\
\text { VSD closed } \\
\text { Quinidine } \\
\beta \text { blocker } \\
\beta \text { blocker, } \\
\text { prednisone } \\
\text { Pacemaker } \\
\text { removed, } \\
\text { WPW surgery } \\
\beta \text { blocker } \\
\text { Quinidine, } \\
\beta \text { blocker } \\
\text { Mexiletine, } \\
\text { amiodarone } \\
\beta \text { blocker } \\
\beta \text { blocker, } \\
\text { procainamide } \\
\beta \text { blocker } \\
\text { Amiodarone }\end{array}$} \\
\hline $\begin{array}{l}C M \\
C M \\
C M \\
C M \\
C M \\
C M \\
C M \\
C M \\
C M \\
\text { VHD } \\
\text { VHD } \\
\text { VHD } \\
\text { VHD } \\
\text { VHD }\end{array}$ & $\begin{array}{l}28, M \\
39, \mathrm{~F} \\
51, \mathrm{~F} \\
55, \mathrm{~F} \\
56, \mathrm{~F} \\
56, \mathrm{M} \\
63, \mathrm{M} \\
68, \mathrm{~F} \\
73, \mathrm{~F} \\
34, \mathrm{M} \\
38, M \\
53, \mathrm{~F} \\
56, M \\
63, M\end{array}$ & $\begin{array}{l}24 \\
27 \\
21 \\
30 \\
24 \\
11 \\
40 \\
39 \\
40 \\
28 \\
62 \\
50 \\
40 \\
43\end{array}$ & $\begin{array}{l}\mathbf{T} \\
\mathbf{P} \\
\mathbf{P} \\
\mathbf{P}, \text { Iso } \\
\mathbf{T}, \text { Iso } \\
\mathbf{P} \\
\mathbf{T}, \text { Iso } \\
\mathbf{T}, \text { Iso } \\
\mathbf{T}, \text { } \\
\mathbf{T}, \text { Iso } \\
\mathbf{T}, \text { Iso } \\
\mathbf{P} \\
\mathbf{P}\end{array}$ & $\begin{array}{l}\text { VF } \\
\text { Sust VT } \\
\text { Sust VT } \\
- \\
- \\
- \\
\text { Sust VT } \\
\text { NSVT } \\
- \\
- \\
- \\
\overline{\text { NSVT }} \\
\text { NSVT }\end{array}$ & $\begin{array}{l}- \\
+ \\
+ \\
- \\
- \\
+ \\
+ \\
- \\
- \\
- \\
- \\
+ \\
+\end{array}$ & $\begin{array}{r}20 \\
63 \\
21 \\
27 \\
5 \\
8 \\
32 \\
5 \\
9 \\
2(\mathrm{SD}) \\
22 \\
3 \\
27 \\
59\end{array}$ & \\
\hline $\begin{array}{l}\text { VHD } \\
\text { HTHD } \\
\text { HTHD }\end{array}$ & $\begin{array}{l}65, \mathrm{~F} \\
52, \mathrm{M} \\
64, \mathrm{M}\end{array}$ & $\begin{array}{l}27 \\
41 \\
55\end{array}$ & $\begin{array}{l}\mathbf{P} \\
\mathbf{P} \\
\mathbf{P}\end{array}$ & $\begin{array}{l}\text { NSVT } \\
\text { Sust VT }\end{array}$ & $\begin{array}{l}- \\
-\end{array}$ & $\begin{array}{l}11(\mathrm{SD}) \\
36 \\
31\end{array}$ & \\
\hline \multirow{2}{*}{$\begin{array}{l}\text { CHD } \\
\text { CHD } \\
\text { MVP } \\
\text { Lymphocytic } \\
\text { myocarditis } \\
\text { WPW }\end{array}$} & $\begin{array}{l}5, M \\
24, M \\
22, F \\
34, M\end{array}$ & $\begin{array}{l}\overline{49} \\
69 \\
60\end{array}$ & $\begin{array}{l}\mathbf{P} \\
\mathbf{P} \\
\mathbf{P}, \text { Iso } \\
\mathbf{P}\end{array}$ & $\begin{array}{l}\overline{-} \\
\text { Sust VT } \\
-\end{array}$ & $\begin{array}{l}- \\
+ \\
-\end{array}$ & $\begin{array}{l}31 \\
32 \\
35 \\
49\end{array}$ & \\
\hline & $58, M$ & - & $T$, Iso & - & - & 12 & \\
\hline $\begin{array}{l}\text { NCHD } \\
\text { NCHD }\end{array}$ & $\begin{array}{l}17, M \\
23, \mathrm{~F}\end{array}$ & $\begin{array}{l}59 \\
64\end{array}$ & $\begin{array}{l}\text { P, Iso } \\
\mathbf{T} \text {, Iso }\end{array}$ & $\overline{-}$ & - & $\begin{array}{l}37 \\
21\end{array}$ & \\
\hline NCHD & $26, F$ & 55 & $\mathrm{~T}$, Iso & - & - & $19(\mathrm{VT})$ & \\
\hline $\begin{array}{l}\text { NCHD } \\
\text { NCHD } \\
\text { NCHD }\end{array}$ & $\begin{array}{l}34, F \\
61, F \\
64, M\end{array}$ & $\begin{array}{l}62 \\
57 \\
50\end{array}$ & $\begin{array}{l}\mathbf{P} \\
\mathbf{P}, \text { Iso }\end{array}$ & $\begin{array}{l}\overline{-} \\
\text { NSVT }\end{array}$ & $\overline{-}$ & $\begin{array}{l}35 \\
40 \\
14\end{array}$ & \\
\hline NCHD & $69, \mathrm{~F}$ & 72 & $T$, Iso & - & - & $\begin{array}{r}1 \\
20\end{array}$ & \\
\hline
\end{tabular}

normal endomyocardial biopsy specimen.

D, congenital heart disease; CM, cardiomyopathy; HTHD, hypertensive heart disease; Iso, isoprenaline; LVEF, left ventricular ejection fraction; 'P, mitral valve prolapse; NCHD, no overt clinical heart disease; NSVT, non-sustained ventricular tachycardia; $P$, double extrastimuli; SD, sudden th; Sust VT, sustained ventricular tachycardia; T, triple extrastimuli; VF, ventricular fibrillation; VHD, valvar heart disease; VSD, ventricular septal :ct; WPW, Wolff-Parkinson-White syndrome.

was reached. The third stimulus was introduced in a similar fashion.

Incremental ventricular pacing for five beats to 2:1 capture or a paced cycle length of $200 \mathrm{~ms}$ was then performed. If no arrhythmia was induced at the right ventricular apex, the catheter electrode was repositioned in the right ventricular outflow tract and the stimulation protocol was repeated. In 19 patients (five in group 1 and 14 in group 2) in whom the above protocol did not induce an arrhythmia, programmed stimulation was repeated during the intravenous infusion of isoprenaline $(0.05 \mathrm{mg} / \mathrm{kg}$ per $\mathrm{min}$ ) or stimulation of the left ventricle or both.

DEFINITIONS

Inducible ventricular arrhythmia, more than five beats of ventricular tachycardia or ventricular fibrillation.

Sustained ventricular tachycardia, arrhythmia continuing for $>30 \mathrm{~s}$ or an intervention (pacing, direct current countershock) was required because of haemodynamic deterioration.

Non-sustained ventricular tachycardia, arrhythmia continuing for more than five beats but for $<30 \mathrm{~s}$ and without associated haemodynamic deterioration requiring intervention.

Successful antiarrhythmic drug treatment, no more than four return ventricular beats during repeated programmed ventricular stimulation.

Sudden death, death within an hour of the onset of symptoms in a patient free of haemodynamic collapse or myocardial infarction in the preceding 24 hours. 


\section{TREATMENT}

Patients who had inducible ventricular arrhythmias underwent serial electropharmacological study to define an effective treatment regimen. If an effective antiarrhythmic drug or drug combination was found, the patient was discharged on that regimen. If an effective drug was not found, the patient was given antiarrhythmic drugs that had either increased the difficulty of induction of arrhythmia at electrophysiological study or decreased the frequency and severity of spontaneously occurring arrhythmias during prolonged ambulatory monitoring. The criteria for the latter varied among individual physicians.

Patients in whom an arrhythmia was not inducible at electrophysiological study were treated according to the individual physician's preference.

Eight patients had cardiac operations after evaluation: coronary artery bypass surgery and mapdirected endocardial resection in three, coronary bypass surgery alone in three, coronary artery bypass surgery and valve replacement in one, and closure of a ventricular septal defect in one.

\section{STATISTICAL ANALYSIS}

Results are expressed as mean (SD). We used logistic regression to assess the possible association of clinical and electrophysiological study variables and the presence or absence of coronary artery disease. Association of the selected variables with time to recurrence or sudden death was evaluated by Cox regression. The assumption of proportional hazards was graphically checked for each covariate; this sug-

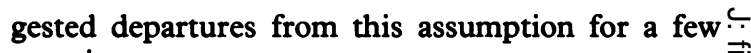
covariates.

We then used a stepwise Cox stratified analysis with presence/absence of one or more previous myo- $\frac{C}{0}$ cardial infarctions as the stratification factor. Within $\overline{\bar{c}}$ these two strata, no other covariates showed any dis- $\widehat{\Phi}$ tinctive departures from the proportional hazards assumption. The same approach was used for overall ${ }^{c}$ survival, although here the New York Heart Associ- $\vec{O}$ ation functional classification appeared to have $a=$ non-proportional hazards structure. After $\stackrel{\sim}{\sim}$ stratification on this covariate (using two strata: functional class 0 or I vs class II, III, or IV), a step- $\vec{c}$ wise Cox stratified analysis was then applied to eval- 0 uate the possible association of the other covariates $i$ with overall survival.

\section{Results}

\section{PATIENTS WITHOUT CORONARY ARTERY} DISEASE (GROUP 1)

Table 1 gives the clinical, angiographic, and electrophysiological features of the 30 patients in group 1.

Electrophysiological study and follow up An arrhythmia was induced in 12 of the 30 patients in group $1(40 \%)$; this was sustained ventricular tachycardia or ventricular fibrillation in seven (fig 1). In seven patients successful pharmacological treat- $\mathbb{\perp}$ ment was predicted from the electrophysiological $\overrightarrow{\vec{O}}$ study; none of these died during follow up. In five 3 patients with an inducible arrhythmia, an effective

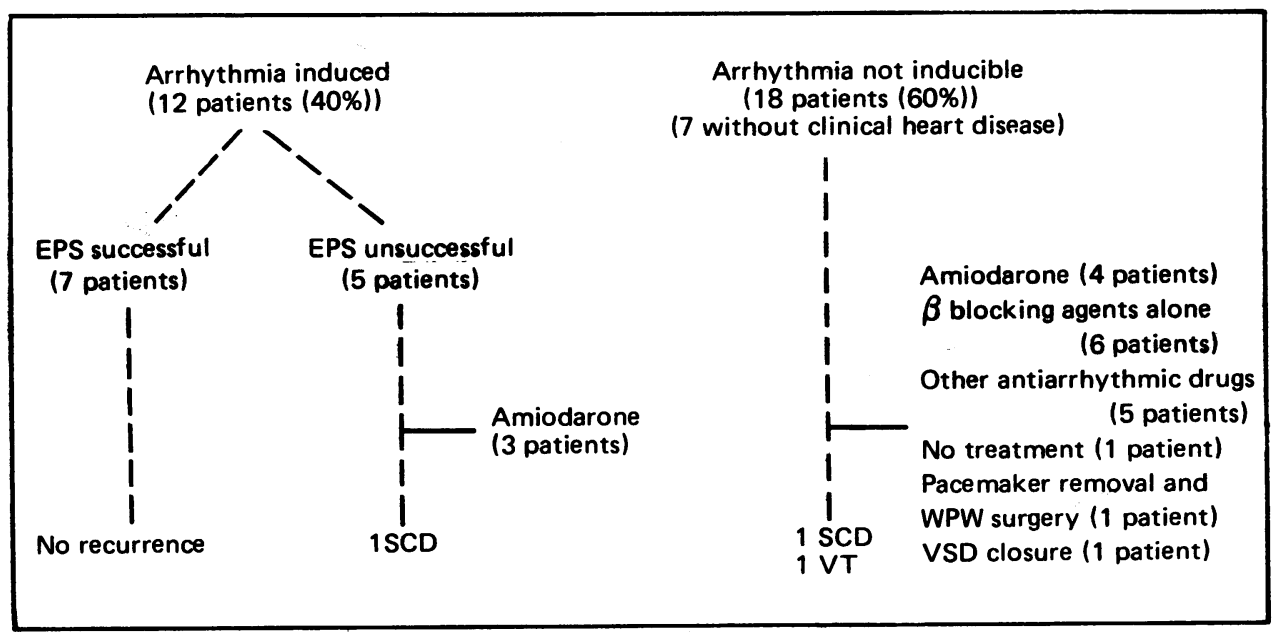

Fig 1 Results of electrophysiological study (EPS), treatment, and follow up in 30 patients without coronary artery disease (group 1). SCD, sudden cardiac death; VT, ventricular tachycardia; WPW, Wolff-Parkinson-White syndrome. 
antiarrhythmic drug could not be identified by electrophysiological study; one patient died suddenly during follow up. An arrhythmia could not be induced in 18 patients; 15 were treated with antiarrhythmic drugs prescribed according to physician preference, a malfunctioning pacemaker was removed from one, a ventricular septal defect was closed in one, and one received no treatment. One patient died suddenly during follow up, and ventricular tachycardia recurred in one patient.

\section{PATIENTS WITH CORONARY ARTERY DISEASE (GROUP 2)}

Table 2 summarises the clinical, angiographic, and electrophysiological features of the 29 patients in group 2.

\section{Electrophysiological study and follow up}

A ventricular arrhythmia was induced in 20 patients $(69 \%)$, with sustained ventricular tachycardia or ventricular fibrillation being induced in 16 (fig 2). Successful pharmacological treatment was predicted on the basis of the electrophysiological study in seven $(35 \%)$; two subsequently died in heart failure and one died suddenly (mean follow up 27 months). Thirteen patients continued to have inducible arrhythmias despite treatment; four (31\%) died suddenly or had recurrent ventricular arrhythmias (mean follow up 15 months) and two died of pump failure before discharge. In nine patients, ventricu-
Table 2 Clinical, angiographic, and electrophysiological variables in 29 patients with coronary artery disease

\begin{tabular}{lcc}
\hline & \multicolumn{2}{l}{ Patients } \\
\cline { 2 - 3 } Variable & No & $\%$ \\
\hline Angina class III or IV & 3 & 10 \\
Previous myocardial infarction & 23 & 79 \\
Aneurysm, left ventricle & 13 & $48^{\star}$ \\
Vessels diseased: & 6 & $26 \dagger$ \\
1 & 7 & $30 \dagger$ \\
2 & 10 & $44 \dagger$ \\
3 or LMCA & 9 & 31 \\
Arrhythmia inducible: & 4 & 14 \\
$\quad$ None & 16 & 55 \\
NSVT & 7 & 24 \\
Arrhyt VT/VF & 7 & \\
drug treatment & & \\
\hline
\end{tabular}

*Percentage of 27 patients who had imaging of the left ventricle. †Percentage of 23 patients who had coronary angiography.

LMCA, left main coronary artery; NSVT, non-sustained ventricular tachycardia; Sust VT, sustained ventricular tachycardia; VF, ventricular fibrillation.

lar arrhythmias could not be induced; four of these had coronary artery bypass surgery. Four (44\%) of the nine patients died suddenly or had recurrent ventricular arrhythmias (one had had coronary artery bypass surgery), and two died of pump failure (one after coronary bypass surgery); the mean follow up was 20 months.

\section{COMPARISON OF PATIENTS IN GROUPS 1} AND 2

Table 3 compares the clinical and electro-

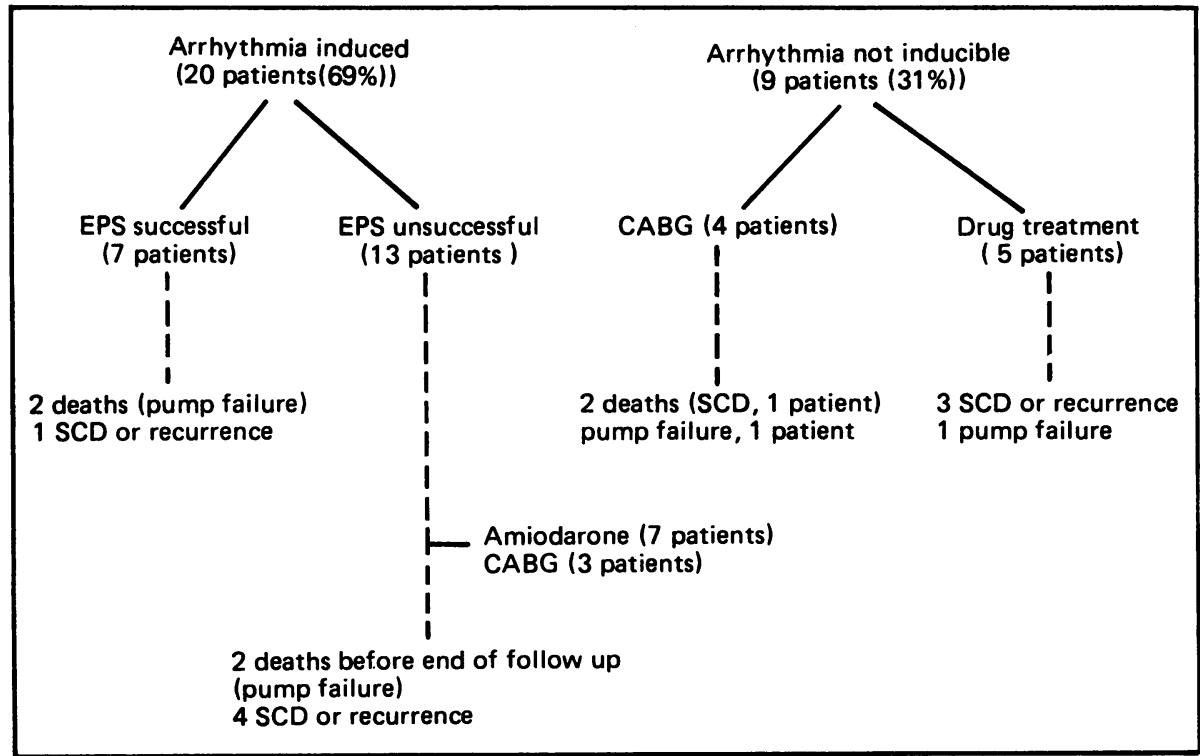

Fig 2 Results of electrophysiological study (EPS), treatment, and follow up in 29 patients with coronary artery disease (group 2). CABG, coronary artery bypass grafting; $S C D$, sudden cardiac death. 
Table 3 Clinical observation and results of electrophysiological study in patients with or without coronary artery disease

\begin{tabular}{|c|c|c|c|}
\hline Variable & $\begin{array}{l}\text { Without } \\
\text { CAD } \\
\text { (group 1) }\end{array}$ & $\begin{array}{l}\text { With } \\
\text { CAD } \\
\text { (group 2) }\end{array}$ & $\begin{array}{l}\text { Univariate } \\
\chi^{2} \\
(1 d f)\end{array}$ \\
\hline $\begin{array}{l}\text { Clinical: } \\
\text { Patients (No) } \\
\text { Mean (SD) age (yr) } \\
\text { Sex }(\% \text { M) } \\
\text { Smoking ( \% never) }\end{array}$ & $\begin{array}{l}30 \\
45(19) \\
47 \\
57\end{array}$ & $\begin{array}{l}29 \\
59(11) \\
76 \\
35\end{array}$ & $\begin{array}{l}7.9 \star \\
5 \cdot 3 \dagger \\
1 \cdot 2\end{array}$ \\
\hline $\begin{array}{l}\text { With: } \\
\text { Hypertension (\%) } \\
\text { Heart failure (\%) } \\
\text { Cardiomegaly (\%) } \\
\text { LV aneurysm (\%) }\end{array}$ & $\begin{array}{r}10 \\
30 \\
37 \\
0\end{array}$ & $\begin{array}{l}52 \\
41 \\
59 \\
34\end{array}$ & $\begin{array}{c}12 \cdot 1^{\star} \\
<1 \\
2 \cdot 9 \\
12 \cdot 5^{\star}\end{array}$ \\
\hline $\begin{array}{l}\text { Ejection fraction: } \\
\text { Mean (SD) (\%) } \\
\text { No < 35\% }\end{array}$ & $\begin{array}{l}45(16) \\
8 \\
0\end{array}$ & $\begin{array}{l}32(17) \\
17 \\
23\end{array}$ & $\begin{array}{r}7 \cdot 3^{\star} \\
39 \cdot 0^{\star}\end{array}$ \\
\hline $\begin{array}{l}\text { Electrophysiological: } \\
\text { Use of triple } \\
\text { extrastimuli (No (\%)) } \\
\text { LV stimulation or } \\
\text { isoprenaline (No (\%)) } \\
\text { Inducible arrhythmia }\end{array}$ & $\begin{array}{l}13(43) \\
14(47)\end{array}$ & $\begin{array}{r}17(59) \\
5(17)\end{array}$ & $1 \cdot 4$ \\
\hline $\begin{array}{l}\text { 1nauciole arrnytnmia } \\
\text { So (\%)) } \\
\text { Sustained (No) } \\
\text { Non-sustained (No) } \\
\text { Other EPS } \\
\text { abnormalities } \\
(\text { No }(\%))\end{array}$ & $\begin{array}{l}12(40) \\
7 \\
5\end{array}$ & $\begin{array}{l}20(69) \\
16 \\
4\end{array}$ & $6.2 \dagger$ \\
\hline $\begin{array}{l}\text { Median time from } \\
\text { arrest to EPS (days) } \\
\text { (25th-75th } \\
\text { percentiles) } \\
\text { (days) } \\
\text { Drug success based } \\
\text { on EPS }\end{array}$ & $(10,61)$ & $(9,36)$ & $\begin{array}{l}1.5 \\
9 \cdot 6^{\star}\end{array}$ \\
\hline
\end{tabular}

CAD, coronary artery disease; EPS, electrophysiological study; LV, left ventricular; MI, myocardial infarction; NS, not significant. *Association with presence/absence of CAD $(p<0.01)$.

+Association with presence/absence of CAD $(\mathrm{p}<0.05)$.

physiological variables in patients with and without coronary artery disease. The patients without coronary artery disease were younger, were more evenly distributed between the sexes, and had a lower frequency for hypertension. Logistic regression analysis indicated that previous myocardial infarction and hypertension were the features most strongly associated with coronary artery disease. No other variables were independently associated with coronary artery disease. The frequencies of clinically apparent heart failure and radiologically apparent cardiomegaly were similar in both groups, but left ventricular ejection fraction was lower in patients with coronary artery disease. There were no differences in stimulation protocols between groups, but more patients without coronary artery disease had left ventricular stimulation or isoprenaline infusion as part of the protocol. This probably reflects the greater ease of induction of arrhythmia by standard stimulation protocols in patients with coronary artery disease.
Median follow up was 13.9 months in the patients with coronary artery disease and 31.2 months in those without coronary artery disease.

In seven patients without coronary artery disease and seven with coronary artery disease, effective treatment was identified by electrophysiological study. During follow up of these patients, none without coronary artery disease died or had recurrence of arrhythmia, but there were four deaths or recurrences in the seven patients with coronary artery disease (pump failure in two).

Amiodarone was given to 14 patients (seven without and seven with coronary artery disease). During follow up, two patients died suddenly and one had a recurrence (total recurrence rate $21 \%$ ).

SURVIVAL

Figure 3 shows the estimated survival (KaplanMeier) for patients with and without coronary artery
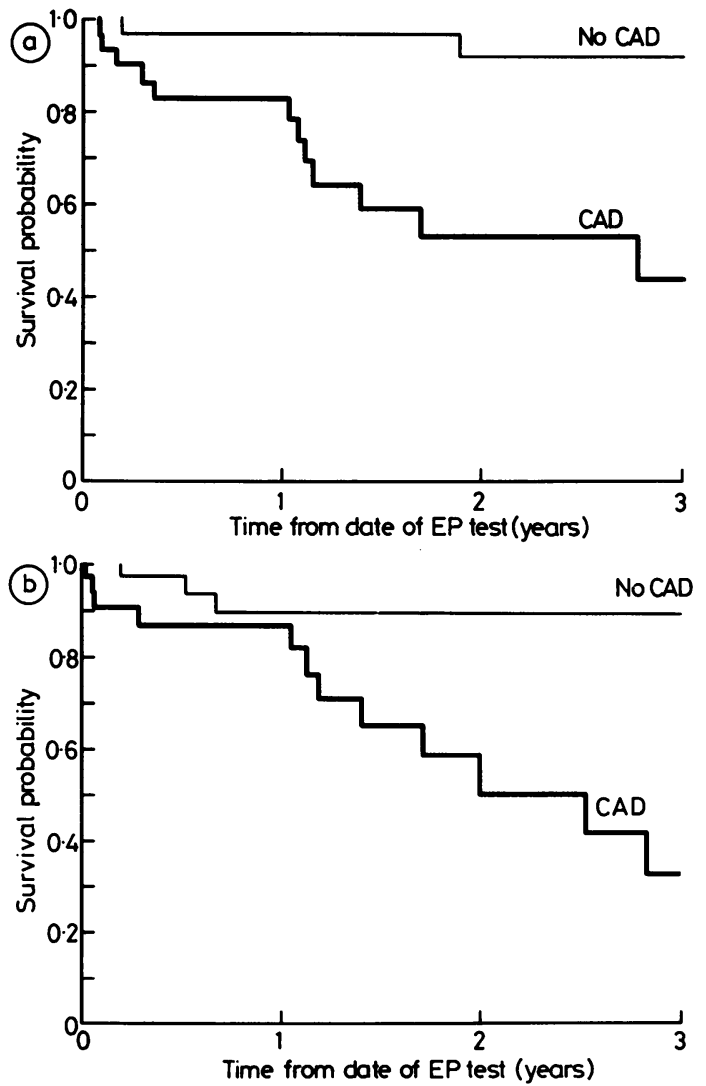

Fig 3 Cumulative survival of patients stratified according to the presence or absence of clinically significant coronary artery disease. (a) Including all causes of death; (b) survival without sudden cardiac death or recurrence of life threatening ventricular arrhythmia. EP, electrophysiological. 
disease. In group 1 , one patient had a recurrence of arrhythmia and survived and two died suddenly. In only one of these three patients was arrhythmia inducible at electrophysiological study (patient 16); however, electrophysiological study did not identify successful drug treatment. In group 2, there were nine sudden cardiac deaths or recurrences of a life threatening arrhythmia. Six patients in group 2 died of myocardial pump failure and three of them had recurrent ventricular tachycardia before death. Thus the total cardiac mortality rate of patients was $7 \%$ in group 1 and $41 \%$ in group 2 . If all cardiac deaths and recurrences of life threatening arrhythmias are included, $10 \%$ of those in group 1 died or had a recurrence compared with $52 \%$ in group 2 .

\section{ANALYSIS BY THE COX MODEL}

For analyses by the Cox model the presence or absence of previous myocardial infarction was used as a stratifying factor when the end point was recurrence or sudden cardiac death and New York Heart Association functional class was used when overall survival was the end point. Univariate analysis of time to recurrence or sudden death showed statistically significant associations with only previous myocardial infarction, left ventricular aneurysm, coronary artery disease, and ejection fraction. When previous myocardial infarction was used as a stratification factor there was no significant association with other variables. The analysis of overall survival indicated that only previous myocardial infarction, coronary artery disease, functional class, and cardiomegaly were univariately associated with survival. The analysis stratified by functional class showed an association with previous myocardial infarction, but when this too was used as a stratifying factor no other factors showed a significant association.

\section{Discussion}

We have shown that patients who survive a cardiac arrest unassociated with an acute myocardial infarction and who do not have underlying coronary artery disease have lower rates of cardiac mortality and arrhythmia recurrence than do similar patients who have documented coronary artery disease $(10 \%$ vs $52 \%$ ); however, this lower mortality is not statistically significant after adjustment for a history of previous myocardial infarction. The strong association between previous myocardial infarction and sudden cardiac death in patients with coronary artery disease is expected and is entirely consonant with pathological and epidemiological data. There were no clinical or haemodynamic predictors of death or recurrence of arrhythmia in the group with- out coronary artery disease. Of the three patients who had recurrences, two had valvar heart disease (one in New York Heart Association functional class II and one in class III; left ventricular ejection fractions were $27 \%$ and $28 \%$, respectively). There were five other patients in the group with similar or lower ejection fractions who remained event free.

Follow up information on survivors of out-ofhospital cardiac arrest who specifically did not have overt coronary artery disease is available only in one previous study. ${ }^{4}$ In that study, 13 of 33 patients with a spontaneous cardiac arrest caused by ventricular fibrillation or ventricular tachycardia did not have coronary artery disease. During a mean follow up of survivors for 29 months, five patients (three with primary electrical heart disease and two with cardiomyopathy) died suddenly or had a recurrence, giving a cardiac mortality and recurrence rate of $38 \%$. In the present series the rate was $10 \%$. Details of left ventricular function and the success of electrophysiological study in the patients without coronary artery disease were not given. The reasons for the difference in mortality and recurrence rate between this study and ours are not apparent, but it may reflect differences in sample size, composition, and treatment. Most importantly, the difference may reflect selection bias, perhaps related to variations in hospital referral practices.

The frequency with which ventricular arrhythmias can be induced in patients without coronary artery disease was significantly lower than that in patients with coronary artery disease $(40 \%$ vs $69 \%)$; again, these differences are not significant when adjusted for a history of previous myocardial infarction. Skale et al recently reported the results of electrophysiological study in 62 survivors of out-ofhospital cardiac arrest; of these, $35 \%$ had coronary artery disease. ${ }^{8}$ As in our series, the inducibility rate was higher in those with coronary artery disease $(85 \%$ vs $60 \%$ ). Skale et al, however, did not present a follow up categorised according to the presence or absence of coronary artery disease.

The overall mortality (including sudden and nonsudden deaths) and recurrence for our total group of patients was $31 \%$, which resembles the $13-39 \%$ reported in previous studies. ${ }^{4-6}$ The striking feature of the present study is the poor outcome in patients with coronary artery disease; $15(52 \%)$ of 29 patients with coronary artery disease died or had recurrent arrhythmias. Myocardial pump failure was the cause of $40 \%$ of the deaths and, given the overall poor left ventricular function in this group (mean left ventricular ejection fraction $32 \%$ ), the presence of severe myocardial damage before the cardiac arrest is the most likely explanation for this observation. 
Studies of outcome in patients who have survived an out-of-hospital cardiac arrest demonstrated an overall mortality and recurrence rate of $32 \%$ at one year and $47 \%$ at two years. ${ }^{1}$ A significant proportion $(27 \%)$ of these deaths were not sudden but were caused by myocardial pump failure. Studies suggest that treatment guided by electrophysiological study reduces overall mortality and recurrence rates, but still a significant number of patients died despite this procedure being followed. ${ }^{4-6}$ Indeed, it would be unrealistic to think that electrophysiological study alone in these patients, many of whom have multivessel coronary artery disease or severely compromised left ventricular function, could define optimal treatment for all. ${ }^{410}$ The electrophysiological study may not reproduce transient dynamic events-for example, ischaemia or an electrolyte disturbance-that may have precipitated the initial cardiac arrest. ${ }^{11-13}$ Clearly, other forms of treatment must be explored in these high risk patients.

\section{LIMITATIONS}

Like similar previous studies, the present one is retrospective and lacks controls. Therefore, our conclusions must be tentative. Furthermore, although it seems logical to compare the subgroup with coronary artery disease with the subgroup without, the influence of selection bias on comparisons of these groups and the various aetiologies within the group without coronary artery disease cannot be determined. Programmed ventricular stimulation was not performed in all patients in the present study after the start of "empiric" antiarrhythmic treatment. This usually occurred in the setting of a negative electrophysiological study at baseline and the perceived need of the attending physician to offer some treatment to a patient who had suffered a cardiac arrest. Thus an arrhythmogenic effect may have been missed in some patients. Nor was programmed ventricular stimulation performed in patients on amiodarone. The recent information ${ }^{14}$ is that suggests that programmed ventricular stimulation in patients on amiodarone treatment is valuable was not available during this study. Finally, the automatic implantable defibrillator was not available to us during the early part of this study; undoubtedly, this device would now be used and may have improved the survival of patients after an out-ofhospital cardiac arrest in whom inducible arrhythmias were not responsive to antiarrhythmic drug treatment and who were not suitable candidates for electrosurgery.

\section{CONCLUSIONS}

Among patients who suffer an out-of-hospital cardiac arrest without an associated acute myocardial infarction those without coronary artery disease seem to have a better prognosis than those who have coronary artery disease. The usefulness of electrophysiological testing in these patients is limited by the low rate of arrhythmia inducibility and the small number of patients who respond to specific antiarrhythmic treatment. Those patients who responded to specific drug treatment, however, did well during the 23 month follow up. Electrophysiological studies therefore seem to be useful in identifying a small number of patients who have an excellent long term prognosis. This emphasises the fact that patients who survive an out-of-hospital cardiac arrest unassociated with an acute myocardial infarction should be comprehensively investigated to define the presence, nature, and severity of the underlying heart disease and that electrophysiological testing has a limited but, none the less, useful role in defining treatment and prognosis.

This study was supported in part by a grant from the Institute of Cardiovascular Research, Brisbane, Australia.

\section{References}

1 Cobb LA, Baum RS, Alvarez H III, Schaffer WA. Resuscitation from out-of-hospital ventricular fibrillation: 4 years follow-up. Circulation 1975, 52(suppl 3):223-8.

2 Liberthson RR, Nagel EL, Hirschman JC, Nussenfeld SR. Prehospital ventricular defibrillation: prognosis and follow-up course. $N$ Engl J Med 1974;291: 317-21.

3 Ruskin JN, DiMarco JP, Garan H. Out-of-hospital cardiac arrest: electrophysiologic observations and selection of long-term antiarrhythmic therapy. N Engl J Med 1980;303:607-13.

4 Benditt DG, Benson DW Jr, Klein GJ, Pritzker MR, Kriett JM, Anderson RW. Prevention of recurrent sudden cardiac arrest: role of provocative electropharmacologic testing. J Am Coll Cardiol 1983;2: 418-25.

5 Roy D, Waxman HL, Kienzle MG, Buxton AE, Marchlinski PE, Josephson ME. Clinical characteristics and long-term follow-up in 119 survivors of cardiac arrest: relation to inducibility at electro- $\overline{\mathrm{N}}$ physiologic testing. Am J Cardiol 1983;52:969-74.

6 Ruskin JN, Garan H, DiMarco JP, Kelly E. Electro- N physiologic testing in survivors of prehospital cardiac arrest: therapy and long-term follow-up [Abstract]. Am J Cardiol 1982;49:958.

7 Morady F, Scheinman MM, Hess DS, Sung RJ, Shen E, Shapiro W. Electrophysiologic testing in the management of survivors of out-of-hospital cardiac arrest. Am J Cardiol 1983;51:85-9.

8 Skale BT, Miles WM, Heger JJ, Zipes DP, Prystowsky EN. Survivors of cardiac arrest: prevention of recurrence by drug therapy as predicted by electro- 
physiologic testing or electrocardiographic monitoring. Am J Cardiol 1986;57:113-9.

9 Sugrue DD, Holmes DR Jr, Gersh BJ, et al. Cardiac histologic findings in patients with life-threatening ventricular arrhythmias of unknown origin. $\mathrm{J} \mathrm{Am}$ Coll Cardiol 1984;4:952-7.

10 Morady F, DiCarlo L, Winston S, Davis JC, Scheinman MM. Clinical features and prognosis of patients with out of hospital cardiac arrest and a normal electrophysiologic study. J Am Coll Cardiol 1984;4:39-44.

11 Deanfield JE, Maseri A, Selwyn AP, et al. Myocardial ischaemia during daily life in patients with stable angina: its relation to symptoms and heart rate changes. Lancet 1983;ii:753-8.
12 Brown MJ, Brown DC, Murphy MB. Hypokalemia from beta ${ }_{2}$-receptor stimulation by circulating epinephrine. N Engl J Med 1983;309:1414-9.

13 Thompson RG, Cobb LA. Hypokalemia after resuscitation from out-of-hospital ventricular fibrillation. JAMA 1982;248:2860-3.

14 Naccarelli GV, Fineberg NS, Zipes DP, Heger JJ, Duncan G, Prystowsky EN. Amiodarone: risk factors for recurrence of symptomatic ventricular tachycardia identified at electrophysiologic study. $\mathrm{J} \mathrm{Am}$ Coll Cardiol 1985;6:814-21.

15 McGovern B, Garan H, Malacoff RF, et al. Long-term clinical outcome of ventricular tachycardia or fibrillation treated with amiodarone. Am J Cardiol 1984;53:1558-63. 